\title{
Laboreal
}

Volume $10 \mathrm{~N}^{\circ} 1$ | 2014

Análise ergonómica do trabalho e formação

\section{Competências coletivas e formação em condução de veículos de socorro num contexto de especialização de bombeiros sapadores em França}

Competencias colectivas y formación en conducción de vehículos de emergencia en un contexto de especialización de bomberos en Francia

Compétences collectives et formation à la conduite d'engins de secours dans un contexte de spécialisation des sapeurs-pompiers en France

Collective skills and training in driving emergency vehicles within a firefighters' specialization context in France

Christine Vidal-Gomel, Catherine Delgoulet e Céline Geoffroy

\section{OpenEdition}

Journals

\section{Edição electrónica}

URL: http://journals.openedition.org/laboreal/5133

DOI: 10.4000/laboreal.5133

ISSN: 1646-5237

Editora

Universidade do Porto

Refêrencia eletrónica

Christine Vidal-Gomel, Catherine Delgoulet e Céline Geoffroy, « Competências coletivas e formação em condução de veículos de socorro num contexto de especialização de bombeiros sapadores em França », Laboreal [Online], Volume $10 N^{0} 1$ | 2014, posto online no dia 01 julho 2014, consultado o 08 outubro 2019. URL : http://journals.openedition.org/laboreal/5133; DOI : 10.4000/laboreal.5133

Este documento foi criado de forma automática no dia 8 outubro 2019

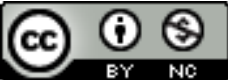

Laboreal está licenciado com uma Licença Creative Commons - Atribuição-NãoComercial 4.0 Internacional. 


\section{Competências coletivas e formação em condução de veículos de socorro num contexto de especialização de bombeiros sapadores em França}

Competencias colectivas y formación en conducción de vehículos de emergencia en un contexto de especialización de bomberos en Francia

Compétences collectives et formation à la conduite d'engins de secours dans un contexte de spécialisation des sapeurs-pompiers en France

Collective skills and training in driving emergency vehicles within a firefighters' specialization context in France

Christine Vidal-Gomel, Catherine Delgoulet e Céline Geoffroy

\section{NOTA DO EDITOR}

http://dx.doi.org/10.15667/laborealx0114cvg

Manuscrito recebido em: agosto/2013

Aceite após peritagem: maio/2014

Agradecemos a Jean-Charles Gilcart que permitiu a realização deste trabalho, ao comando do SDIS, à equipa da EDIS, e a todos os sapa-dores bombeiros que colaboraram.

Agradecemos também a Deborah Gebaï que contribuiu com recolha de dados e com a elaboração de uma metodologia de análise.

E ainda, Jacques Leplat e os dois revisores indicados pela revista, que nos permitiram melhorar a versão inicial do documento com os seus comentários e sugestões.

o presente estudo responde ao pedido da École Départementale d'Incendie et de Secours (EDIS) - uma escola departamental de combate ao incêndio e socorro de 
bombeiros sapadores, localizada na região de Île-de-France. Trata-se de levar a cabo uma análise da atividade de condução de dois tipos de camiões - o veículo de combate a incêndios pesado (VCIP) e o veículo de socorro rodoviário (VSR) - a fim de contribuir para a melhoria da formação de motoristas de veículos pesados de socorro, conforme proposto pela EDIS.

2 Este estudo foi realizado no contexto da implementação de uma nova organização do trabalho. Embora até agora todos os bombeiros com habilitação de condução de veículos pesados pudessem conduzir um veículo (VCIP ou VSR) e participar em todas as operações de acordo com a sua função, o comando do Service départemental d'incendie et de secours (SDIS) - serviço departamental de combate ao incêndio e socorro -, do qual depende a EDIS, decidiu formar um grupo especializado na condução de veículos pesados, que ficará inteiramente encarregue de realizar a tarefa de condução. Esta decisão é uma resposta ao número de acidentes rodoviários envolvendo veículos de emergência, considerado muito alto pela gestão do SDIS, que poderá estar associada a uma falta de mestria na condução destes veículos pesados por parte dos condutores. Assim, uma formação com vista à "especialização" foi concebida e será concretizada quando a equipa de ergónomos for solicitada para tal.

Os operacionais, que concordaram em tornar-se especialistas na condução e que vão receber formação, já têm carta de condução de veículos pesados. Os formadores são bombeiros sapadores profissionais ou bombeiros voluntários que integraram a EDIS. Um deles era formador em condução e segurança rodoviária. A formação decorre em sala e em pistas de treino e tem uma forte componente sobre as regras do código da estrada. As relações com o conteúdo do trabalho não são apresentadas. Ora, mesmo para os não profissionais da estrada [1], a atividade de condução depende em parte das condições de realização do trabalho (Forrierre \& Six, 2010; Fort, Pourcel, Davezies et al, 2010), pois está fortemente incorporada na própria profissão. O estudo aqui apresentado tem também como objetivo questionar e melhorar a "formação para a especialização", tendo em conta as especificidades da atividade de bombeiro sapador; permite ainda um novo olhar sobre a escolha da nova organização do trabalho, à luz das práticas reais em situações de emergência. Para isso, interessamo-nos particularmente na condução dos veículos durante as viagens para o local da intervenção de emergência, a fase determinante em que se concentram os riscos rodoviários (Vidal-Gomel, 2010).

4 Para entender essas questões, propomos caracterizar a condução e a condução de veículos de socorro, especificamente; as atividades e as competências [ $\left.{ }^{2}\right]$ coletivas envolvidas na condução serão então discutidas. Será discutido o método bem como os resultados, nomeadamente as estratégias de condução dos bombeiros, os conceitos e variáveis que elas incorporam e as competências coletivas solicitadas na condução de veículos de socorro. Em conclusão, discutimos formas de contribuir para a formação e para compreender as consequências das escolhas organizacionais. 


\section{Condução automóvel e a específicidade da conduçao de veículos de socorro dos Bombeiros Sapadores}

5 A condução é geralmente caracterizada como uma atividade de deslocação com um veículo, evitando os perigos (Neboit, 1978). Este é um domínio da atividade que depende do controlo do ambiente dinâmico (Hoc, 1996); o ambiente rodoviário desenrola-se, em parte, de forma independente da ação do operacional, devido à inércia do veículo e ao comportamento dos outros utilizadores do espaço rodoviário. Esta tarefa é complexa e exige a perceção, a compreensão da situação e o antecipar da sua evolução, com vista à ação. A consciência da situação [3], que integra estes três aspetos (Endsley, 1995), é, então, crucial: uma insuficiente consciência da situação está associada a risco de acidente (Kaber \& Endsley, 1998).

6 A consciência da situação aqui é entendida a partir das contribuições da didática profissional, que enfatiza a importância dos conceitos pragmáticos [4] na compreensão de situações e na antecipação (Pastré, 2005). Com o desenvolvimento dos conceitos pragmáticos, a compreensão das situações é refinada, assim como a categorização das situações. Os indicadores, que são articulados com os conceitos pragmáticos e nos quais se baseia a aquisição de informação, diversificam-se. O desenvolvimento destes conceitos também está associado com a implementação de estratégias proactivas e com a antecipação de fenómenos (Samurçay \& Pastré 1995; Pastré, 2005). Os trabalhos de Caens-Martin (2005) acerca do tamanho da vinha fornecem sobre esta matéria uma ilustração detalhada. A didática profissional permite simultaneamente dar conta das competências profissionais focando a conceptualização para a ação e servir como uma ferramenta para a conceção de situações de formação (Samurçay \& Rabardel, 2004; Pastré, 2005b). Lefebvre (2001) identificou certos aspetos da condução colocando em evidência quatro conceitos pragmáticos: zona de inércia, campo das trajetórias possíveis, força resultante da curva e comportamento incerto.

7 O quadro que o autor propõe inscreve-se na linha dos modelos hierárquicos da atividade de condução (Michon, 1985; Van Der Mollen \& Böticher, 1988). Tem quatro componentes, das quais as duas primeiras estão encaixadas uma na outra.

- controlo instrumental do veículo, "condução", diz respeito à manipulação dos comandos, o controlo e a antecipação das leis físicas (inércia, trajetórias).

8 Vários conceitos pragmáticos estão envolvidos na condução (p. 28-30):

\footnotetext{
"A zona de inércia (ou zona de liberdade) é definida como o espaço virtual que precede o veículo em movimento e é definido como a soma das distâncias teóricas de latência e de travagem, sob dadas condições [...].

o campo das trajetórias possíveis esquematiza a rigidez longitudinal do movimento em função da velocidade e dos limites de aderência para produzir uma aceleração centrípeta [...].

A força global resultante em curva [é composta por um conjunto de forças que se aplicam]: peso, força centrífuga e inércia em caso de variação da
} 
velocidade. [Ela determina a estabilidade do veículo, que é um] fenómeno

observável e apreciável propriocetivamente." (tradução livre).

- A adaptação ao ambiente e ao tráfego, o segundo nível, diz respeito à identificação das situações e à comunicação operacional com todos os outros utilizadores do espaço rodoviário. O conceito de "comportamento incerto" é um conceito pragmático que se refere aos possíveis comportamentos dos outros atores, e que leva a tomar precauções, como não ultrapassar ou aumentar a distância (Lefebvre, op. cit.). Esta tomada em consideração do comportamento dos outros utilizadores da estrada foi particularmente analisada por Mundutéguy \& Darses (2007) que destacam a existência de referências comuns que consideram um "ambiente cognitivo supostamente comum" aos atores da situação. Eles explicam as expectativas que temos em relação aos outros utilizadores. Estes autores observam também as antecipações do comportamento dos outros veículos envolvidos na gestão dos riscos. Elas baseiam-se em vários tipos de indicadores, tais como a posição, a trajetória, a velocidade dos veículos ao redor, bem como as ações tomadas ou não por outros condutores, e as características específicas dos veículos.

- A organização e planificação das deslocações, terceiro nível, remete para a preparação do trajeto a longo prazo e à navegação no momento da condução.

- Finalmente, o metaconhecimento sobre a tomada de consciência e o conhecimento de seu próprio funcionamento (Valot, 2001). Estes fatores envolvem os outros três níveis do modelo.

9 Estes quatro componentes estão em constante interação durante a atividade de condução e envolvem três dinâmicas: as leis da física, integradas com a mestria instrumental do veículo; o trânsito, integrado com os dois componentes intermediários; e o funcionamento cognitivo e psíquico do condutor, integrado nos quatro níveis.

A condução de veículos pesados, tais como os dos bombeiros sapadores, apresenta uma série de especificidades em termos de condução, como o risco de tombar que está relacionado com as características do veículo, e cuja prevenção implica que se integrem os princípios da inércia, de carga e de massa (Têtard, Quincy, Rougemoux \& Vulin, 1992). De forma complementar, Falkmer e Nordmark (2002) identificam os seguintes fatores de risco: tamanho, peso e capacidade de manobra dos veículos.

11 As características das situações de trabalho dos bombeiros sapadores aqui consideradas têm ainda outras especificidades em relação à condução de veículos pesados. Os trajetos são bastante curtos, na ordem de alguns minutos, e, frequentemente em situação de emergência: é o percurso entre o quartel e a chegada ao local do acidente. Além disso, os estudos sobre "veículos de emergência e socorro a vítimas" (VESV), outros tipos de veículos, foram capazes de identificar atividades coletivas entre o motorista e o chefe da guarnição (CG) [5]. Este último aciona a sirene [6], em função das características das situações, antecipando a sua evolução e em coordenação com a atividade de condução (Vidal-Gomel, 2010; Parage \& Ferrand, 2012). Assim, afigura-se necessário levar em conta as atividades coletivas na nossa análise, abordagem original no estudo da condução de veículos pesados, que na maioria das vezes é vista só no sentido individual (o do motorista, sozinho na sua cabine).

\section{Atividades e competências coletivas}

Uma atividade coletiva define-se pela existência de um objetivo comum para as atividades em curso e/ou pela interdependência das atividades de diferentes 
operacionais envolvidos na sua prossecução (Rogalski, 1994; Barthe \& Queinnec, 1999). As tipologias das atividades coletivas são numerosas e os termos usados polissémicos (Barthe \& Queinnec, 1999). Usamos a tipologia de Rogalski (1994), que se aplica a situações em que as tarefas coletivas pré-existem ao grupo de atores que as deve executar e que são definidas pela organização do trabalho, o que corresponde à organização do coletivo de intervenção nos bombeiros sapadores. Dessa tipologia apresentamos aqui apenas as dimensões horizontais, que se referem aos atores do mesmo nível, que é o que nos interessa mais. Várias formas de atividades coletivas podem ser diferenciadas. Apresentamo-las de seguida da mais cooperativa à menos cooperativa. A colaboração corresponde às situações em que os operacionais partilham uma tarefa prescrita e a realizam juntos, sem definir as subtarefas a serem executadas por cada um. A cooperação distribuída corresponde às situações em que os operacionais partilham um objetivo comum, a médio ou longo prazo, mas têm objetivos imediatos distintos. A identificação, a distribuição das tarefas e sincronização das atividades são aqui os pontos-chave. Última dimensão desta tipologia: a co-ação. Aqui, os operacionais não têm nenhum objetivo comum, mas estão presentes no mesmo espaço de trabalho e, eventualmente, partilham recursos. A atividade coletiva é, então, definida a minima conforme requerido pela gestão das interferências entre as atividades dos atores envolvidos (Hoc, 2001).

13 A cognição coletiva ("team cognition"), é considerada um ponto-chave para a cooperação (Salas, Rosen, Burke et al., 2007). Assim, a colaboração e a cooperação distribuídas exigem o desenvolvimento e a manutenção de um referencial operativo comum (Terssac \& Chabaud, 1990; Hoc, 2001), que abrange a representação ocorrente e distribuída da situação e dos conhecimentos que isso requer (Giboin, 2004). 0 conceito de referencial operativo comum pode ser comparado com o de "consciência situacional partilhada", que contém a definição dada ao nível individual da "consciência situacional" (Endsley, 1995) para explicar o desempenho do coletivo (Salas, Prince, Baker \& Shrestha, 1995). Além disso, a colaboração e a cooperação distribuída podem também exigir a sincronização temporal das atividades e sincronização cognitiva (Rogalski, 2005).

14 A estes diferentes níveis que se referem à cooperação na ação e /ou na sua planificação, Hoc (2001) acrescenta a metacooperação: construção de um modelo de si mesmo e dos outros, que nós interpretamos como um modelo das competências dos colegas de uma equipa, dos seus limites, dos constrangimentos que lhes surgem no enfrentar de cada situação e da sua necessidade de ajuda.

Dois aspetos das competências do coletivo devem ser distinguidos: as competências individuais para a ação coletiva e as competências coletivas (Rogalski, 2005). Além das competências técnicas necessárias para a realização das tarefas, as competências individuais orientadas para o trabalho em equipa dependem da assertividade na comunicação e da orientação da sua atenção para os outros - partilha de informação, debate sobre as representações dos outros, regulação da comunicação e seu controlo (reconhecimento, monitorização da compreensão), ter em conta a distribuição da carga de trabalho na equipa, etc. - sem abandonar as suas próprias tarefas e ser capaz de solicitar ajuda, se necessário. Comparativamente, as competências coletivas são, então, definidas como as competências holísticas da equipa, que podem ser analisadas como sendo um único operacionaL, virtual (Rogalski, 1994). 
16 As competências coletivas não são redutíveis à soma das competências individuais (Leplat, 2000; Salas et al. 2007; Largier, Delgoulet \& De La Garza, 2008), elas codeterminam-se (Leplat, 2000). As áreas de sobreposição de competências individuais numa equipa de trabalho são determinantes para a construção de competências coletivas. Em contraste, as competências coletivas enriquecem as competências individuais, especialmente no que diz respeito ao lado comunicacional do trabalho. As competências de cada um opõem-se tanto quanto elas se complementam; as competências coletivas constroem-se assim no seio de jogos de atores sociais, durante um certo período e de forma não-linear (Reynaud, 2001).

o desenvolvimento de competências profissionais individuais e coletivas, joga-se na interação com as situações de trabalho, na necessidade de pôr à prova e de ultrapassar o que foi adquirido. Depende de uma dupla orientação da atividade: a orientação produtiva voltada para a produção de bens e de serviços materiais ou não, e a orientação construtiva que se refere ao desenvolvimento do indivíduo; estes dois aspetos da atividade são ao mesmo tempo conjuntos e distintos (Samurçay \& Rabardel, 2004). Outros aspetos do desenvolvimento de competências são destacados a partir da noção de "coletivo de trabalho". A sua existência e manutenção são precisamente uma das condições para o desenvolvimento de competências individuais e coletivas. Um coletivo de trabalho é definido pelo facto de os operacionais contribuírem para um trabalho comum no cumprimento das normas ( $\mathrm{Cru}, 1988$ ). O coletivo de trabalho compreende um sistema de valores, modos de ser com os outros e os objetos do trabalho, e define o que é desejável ou proibido fazer (Caroly \& Clot, 2004). O coletivo de trabalho é uma das condições que favorecem o desenvolvimento de competências, na medida em que a sua vitalidade permite que se coloquem em debate maneiras de fazer, o que permite que elas evoluam. Ao mesmo tempo, uma das condições para a existência do coletivo de trabalho é precisamente o trabalho coletivo no qual se joga a coordenação das atividades individuais (op. cit.).

A partir deste quadro de análise, o presente estudo procura caracterizar as competências individuais e coletivas envolvidas na condução de veículos de socorro em situação de emergência por bombeiros sapadores. Pretendemos menos uma comparação dos trabalhadores entre eles, ou das formas de conduzir em função do tipo de veículo, e mais uma compreensão do todo suficiente para apresentar propostas de formação e discutir as escolhas organizacionais. Mais especificamente, por um lado, o nosso objetivo é fazer recomendações para a formação tendo em conta a diversidade das estratégias pertinentes que podem ser implementadas, e destacando os conceitos pragmáticos que lhes estão subjacentes. Por outro lado, as escolhas organizacionais são examinadas, sobretudo os seus efeitos sobre o potencial de desenvolvimento das competências dos condutores. Isto levar-nos-á a completar os contributos de Lefebvre (2001) e Mundutéguy \& Darses (2007). De facto, se esses autores têm em conta as dimensões coletivas presentes no contexto rodoviário, eles também acreditam que um motorista conduz sozinho, por si mesmo. Trata-se agora de identificar o conjunto das características de atividade coletiva, nos seus aspetos produtivos e construtivos (Samurçay \& Rabardel, 2004) para entender os impactos da decisão de especialização na condução de bombeiros na sua atividade diária, mas também para a sua formação. 


\section{Terreno e métodos}

19 O estudo foi realizado em dois quartéis no mesmo SDIS de île-de-France, compostos, respetivamente, por 75 e 64 bombeiros sapadores profissionais e voluntários. 0 estudo centra-se em dois tipos de veículos de socorro: veículo de combate a incêndio pesado (foto 1) e veículo de socorro rodoviário (foto 2).

$\mathrm{O}$ veículo de combate a incêndio pesado (VCIP) pesa 8,4 toneladas ( $\mathrm{t}$ ) vazio e $15 \mathrm{t}$ carregado [7] (altura: 3,5 m, largura e comprimento: 2,5 X 7,5 m, área: 18,5 $\mathrm{m}^{2}$ ). Este veículo intervém em caso de incêndio. 0 motorista e o CG estão localizados na parte da frente e quatro bombeiros vão na parte traseira. A frequência de utilização é de 60 saídas no primeiro centro e 80 no segundo, durante um período de dois meses [8].

Foto 1: 0 veículo de combate a incêndio pesado

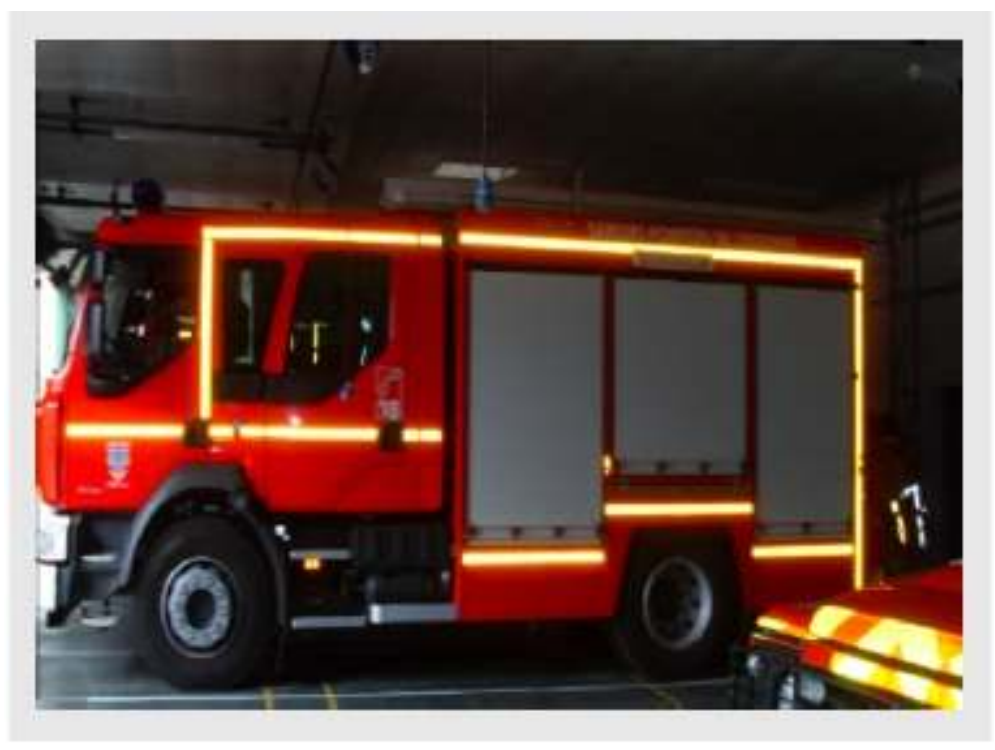

Foto to veiculo de combate a incendlo pesado

210 veículo de socorro rodoviário (VSR) pesa $5 \mathrm{t}$. vazio e $8 \mathrm{t}$. carregado (altura: 3,3 m, largura e comprimento: 2,3 X 5,4 m, área : $12,5 \mathrm{~m}^{2}$ ). Três operacionais estão localizados na parte da frente (o CG, o motorista e um tripulante). É usado em situação de acidente, para desencarcerar os ocupantes do veículo. A frequência de utilização é de, respetivamente, 60 e 40 saídas, para o mesmo período. 
Foto 2: 0 veículo de socorro rodoviário

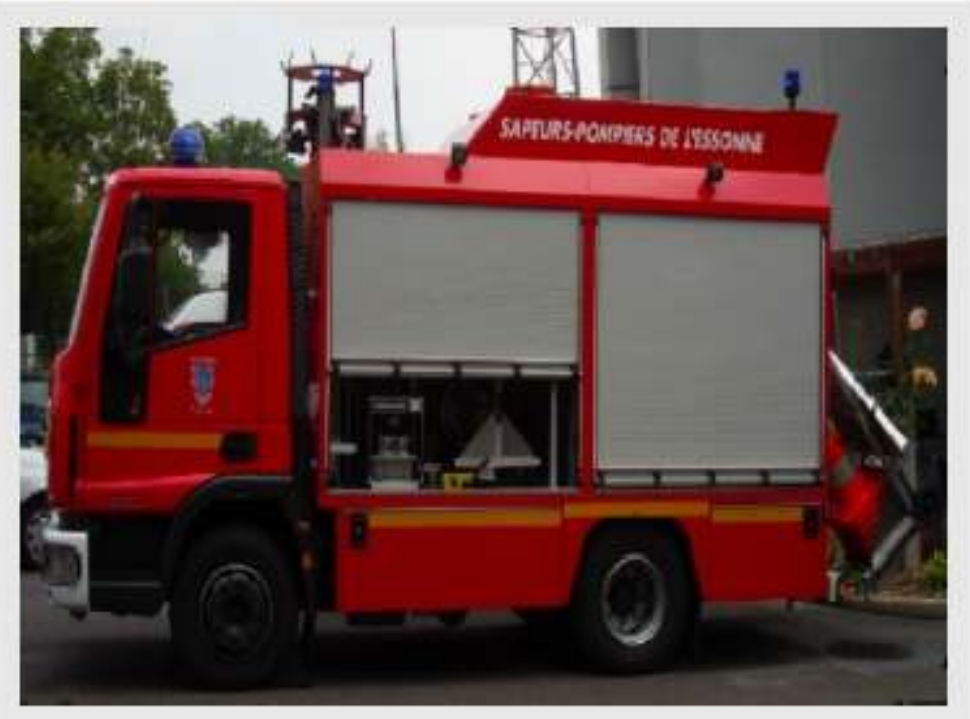

Foto 2: O velculo de socorro rodoviário

Realizámos entrevistas exploratórias com cinco operacionais [] que concordaram em tornar-se especialistas na condução de veículos e que seguiram a formação proposta. $O$ guião de entrevista incluiu questões gerais sobre o percurso de cada um, a sua definição de condução em situação de emergência, as especificidades dos veículos, a formação, o programa de especialização, etc. Também assistimos a uma formação de "especialização" e conversamos com os formadores, nomeadamente para compreender os objetivos e o conteúdo da formação.

Esta fase exploratória levou-nos a concentrar a investigação sobre as saídas do piquete, ou seja, os trajetos entre o quartel e o local do sinistro, que correspondem à fase de condução em situação de emergência; também se identificou o modo de recolha de dados.

Foram filmadas vinte e quatro saídas do piquete: dezasseis com VCIP e oito com VSR. Estas saídas do piquete tiveram como motivo: um pedido de desinfestação de himenópteras; onze incêndios ou suspeitas de incêndio; três declarações de odor suspeito ou risco de intoxicação com $\mathrm{CO}^{2}$, oito acidentes rodoviários; num caso não tivemos acesso à informação dada no momento da saída. Os filmes têm uma duração de 10 minutos, no máximo, que é o tempo limite para chegar aos locais dos sinistros.

Na medida em que nós não poderíamos estar no interior do veículo [10], colocamos uma câmara a bordo. Foi colocada sobre o para-brisas, virada para a estrada. A instrução de utilização era de que a câmara deveria ser ativada pelo motorista, desde a saída do quartel e até chegarem ao local da intervenção. As filmagens dão-nos acesso ao tráfego e às infraestruturas, às mudanças de direção ou de via. As acelerações e as travagens são percetíveis. No entanto, o ruído do motor cobre a maioria das interações entre os operacionais.

26 As filmagens das saídas do piquete que selecionámos para a análise são aqueles para as quais dispomos de autoconfrontações individuais (ver Figura 1) feitas com o motorista. O número de filmagens por operacionais é desigual (1 filme para sete operacionais 
diferentes; 2 filmes para outros três operacionais; 3 filmes para um outro operacionais; 4 filmes para um operacionais e 6 filmes para outro operacional). 0 número de filmagens dependeu das saídas efetuadas ao longo do piquete e da disponibilidade dos operacionais para realizar as autoconfrontações. A recolha de dados foi realizada ao longo de vários dias de piquete, e há saídas tanto com VCIP como com VSR com 4 operacionais.

Figura 1: Exemplo de autoconfrontação

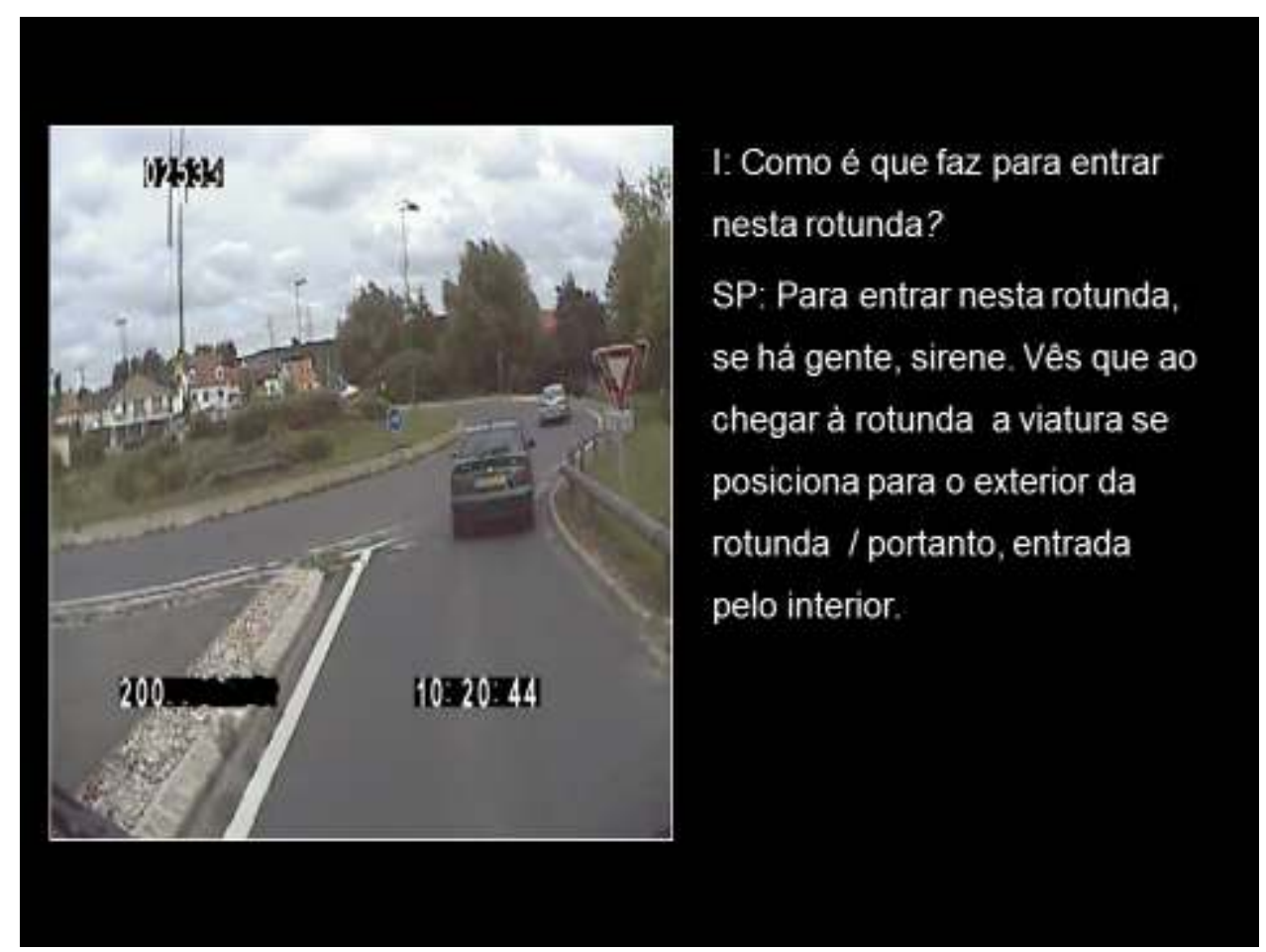

Dispomos de filmagens de saída do piquete e de autoconfrontações de treze operacionais [11]. As autoconfrontações, conduzidos por ergónomos-investigadores da equipa, não puderam ser realizadas imediatamente após as intervenções, mas sim um ou dois dias depois, em função das folgas dos operacionais, especialmente porque decorreram durante o horário de trabalho. As autoconfrontações variam em termos de duração, dependendo da duração das saídas e do tempo disponibilizado pelos operacionais. Deixamos o filme desenrolar-se e cada operacional podia parar a gravação para esclarecimentos sobre sua atividade de condução. As intervenções do investigador centraram-se nas situações de condução atípicas identificadas em visualização anterior. Os objetivos foram, em primeiro lugar, identificar as diferentes estratégias de condução utilizadas e as diferentes atividades coletivas envolvidas (ver Figura 1), em ambas as suas dimensões produtivas e construtivas.

28 As situações "atípicas" identificadas incluíram as transgressões das regras de trânsito estabelecidas e as exceções ao código da estrada permitidas para os bombeiros em condução de emergência (cortar nas curvas, entrar em cruzamentos em contramão, passar o semáforo vermelho, por exemplo). Estas são "situações de ação características" (Daniellou, 1992). As autoconfrontações foram transcritas na íntegra [12]. 


\section{As estratégias de condução dos Bombeiros Sapadores}

29 A partir do momento em que a ordem de saída do piquete é dada, os bombeiros sapadores devem comparecer nos locais no mínimo de tempo possível. O seu objetivo é chegar o mais rápido possível, sem se colocar em perigo e sem causar risco para os restantes utilizadores da estrada: "O objetivo da condução em emergência é colocar o veículo e o pessoal o mais rapidamente possível no local da intervenção, sem colocar a vida dos outros em perigo. 0 ideal é encontrar a melhor relação entre as duas coisas" (SP3). Aqui encontramos uma característica definida por um bombeiro sobre condução de emergência com um VESV (Vidal-Gomel, 2010): "A condução em situação de emergência é conduzir depressa lentamente".

Este conflito de metas requer a implementação de estratégias, em que o princípio é o de conduzir da forma mais fluida e mais ágil possível; isto é, de forma não agressiva para outros utentes da estrada: "Chegando o mais rápido possível, ou seja, com a condução mais fluida, sem que seja agressiva" (SP3). A fluidez foi identificada por Parage \& Ferrand (2012) como um conceito pragmático, organizador da condução de VESV. Da mesma forma que estes autores, reconhecemos que o conceito de fluidez é pouco verbalizado como tal, mas é consistente com várias expressões utilizadas como "evitar cortar", "não conduzir de forma agressiva", "evitar travar ou acelerar", etc. Está implícito, por exemplo, na seguinte verbalização: "Num semáforo, se para mim está vermelho, mas eu vejo o que o outro conseguiu ainda passar com o vermelho, eu sei que vai ficar verde para mim e portanto não preciso de travar" (SP9). Assim, podemos analisar a fluidez como um conceito pragmático.

31 Conduzir de forma fluida requer a implementação de várias estratégias que implicam a condução ou a gestão dos outros utilizadores da estrada.

\subsection{Estratégias baseadas principalmente na condução}

Uma condução fluida supõe adaptar o trajeto do veículo. Por exemplo, numa série de curvas, o condutor que tem boa visibilidade opta por adotar uma linha reta e, portanto, cruza a linha contínua no meio da estrada: "Se tu quiseres, se eu realmente tiver que seguir o Código da Estrada e me posicionar à direita, vês a curva que isso implica? Ou eu realmente abrando para evitar a oscilação ou eu assumo mais riscos, porque quando tu viras, tu tens menos aderência... quando guinas o volante. E assim és obrigado a guinar o volante" (SP9). Um outro operacional explica quais as variáveis situacionais que leva em consideração para cortar ou não uma curva: "É preciso prestar atenção à dimensão, porque pode-se embarrar nalguma coisa. Tem que se ter cuidado, porque se há um estreitamento da via [...] para fazer a curva deve haver espaço para se desviar do lado oposto, e não pode ser" (SP1).

Manter a trajetória o mais direita possível é uma estratégia também levada a cabo durante a travessia de rotundas. Integra, como a estratégia anterior, o evitamento da oscilação e a menor aderência dos pneus, que estão envolvidos no risco de tombamento. Trata-se de entrar na rotunda pelo lado de dentro, como o explica um bombeiro sapador : "Visto que eu vou a sair da rotunda, não me vou encostar à faixa da direita, porque isso vai-me fazer cortar a minha curva, pois seria preciso que eu abrandasse um pouco mais, do que se for por dentro. Portanto, ali fui um pouco à larga e eu estava na faixa da esquerda. Isso 
permitiu-me continuar numa curva espaçada e evitar de abrandar; [não entrar na rotunda pelo exterior permite] reduzir a oscilação e aumentar a aderência dos pneus. Quanto mais guinas o volante, menos aderência tens, obrigatoriamente" (SP11).

A dimensão do veículo e o tamanho das rotundas estão entre as variáveis que são tomadas em consideração, por exemplo: "Esta é a história da dimensão. Depois, depende do tamanho da rotunda. Há rotundas enormes, onde tu não tens que te preocupar em fazer estas coisas. Mas as rotundas pequenas como essa com a dimensão que tem, especialmente com a dimensão, por exemplo, é melhor entrar mais largo; porquê? Porque caso contrário, há a roda, a da traseira esquerda, há a roda de trás da esquerda que vai reclamar" (SP4).

Esta estratégia dos motoristas contradiz a regra prescrita e defendida pelos formadores. De facto, um veículo pesado deve entrar na rotunda pelo lado de fora, de modo a não ser um obstáculo para o tráfego que quer sair da rotunda. De acordo com um dos formadores, isto "fecha o ângulo aos outros condutores e facilita a sua saída". Fazer a rotunda pelo exterior também permite evitar o efeito de oscilação. Um outro formador diz: "Conceção das rotundas é em relevo, portanto pelo exterior evita-se a oscilação. Caso contrário, em caso de travagem de emergência, há o risco de tombar".

A estratégia dos operacionais leva em conta os riscos identificados pelos formadores, mas também inclui a tendência dos outros condutores em dar prioridade aos bombeiros encostando-se à direita, para fora. Para os operacionais, trata-se realmente de gerir conjuntamente vários riscos: o tombar do veículo, o constrangimento de um outro veículo, o prever a colisão, mas, também, no VCIP, os colegas de equipa que poderiam ser feridos em mudanças bruscas de direção. Encontramos também este objetivo na maneira com que podem ser feitas as curvas: "Então sim, nas curvas, se eu as faço mais largas isso depende da infraestrutura, isso que me mostra é para não fazer oscilar a tripulação, por isso eu mantenho a minha trajetória e a minha velocidade" (SP4).

Vários tipos de variáveis são levadas em conta pelos motoristas ao fazer uma curva ou uma rotunda: a oscilação, a aderência, a dimensão, a infraestrutura e a visibilidade. Essas variáveis são consistentes com dois conceitos pragmáticos identificados por Lefebvre (2001): o campo das trajetórias possíveis, a força resultante da curva. No entanto, o conceito central organizador da atividade parece ser o da fluidez da condução, conceito subjacente às estratégias de condução que analisámos e que as organiza. Além disso, este conceito também se articula com outro aspeto da condução, ausente do modelo de Lefebvre, mas derivado da organização da intervenção dos bombeiros sapadores: as suas estratégias têm em conta a presença de colegas na parte de trás do VCIP. Voltaremos a isto mais tarde em maior detalhe na parte consagrada às atividades coletivas (o Esquema 1, mais à frente, apresenta um resumo).

\subsection{Estratégias baseadas principalmente na gestão de outros utilizadores da estrada}

Damos dois exemplos de estratégias de condução com base na gestão dos outros utilizadores do espaço rodoviário: controlá-los para os impedir de passar e evitar causar o pânico. 


\subsubsection{Controlar os outros utilizadores da estrada, impedindo-os de passar} se na faixa de rodagem de forma a impedir que outros condutores interfiram. Reduzem as possibilidades de ação destes. Assim, os comportamentos deles não afetam a progressão do veículo pesado e/ou são mais previsíveis. Além disso, o posicionamento na faixa de rodagem é uma maneira dos bombeiros comunicarem as suas intenções aos outros utilizadores da estrada. Os exemplos seguintes ilustram esta estratégia: "[o veículo está no centro da faixa de rodagem ] isto é por causa das prioridades à direita. Isto permite-me ter que travar menos do que se ficasse na minha faixa porque se há alguém que vem da direita, eu tenho menos necessidade de fazer movimentos de direção para me desviar para a faixa da esquerda e posso tomar a faixa da esquerda, porque não vem ninguém de frente" (SP6).

"Lá, eles viram-me, eu já sei. Eu não precisava de ficar na faixa da direita, eu posso encostar-me imediatamente. Isto dá uma indicação mais para aqueles que vêm de frente. Eles sabem que estás a pedir prioridade. Se ficares à direita, talvez eles hesitem e passem. Se estiveres no meio, as pessoas não vão insistir. Quando te impões, quando tu te mostras, não escapes às pessoas. Às vezes, passas um pouco de força. [...] Isto é, já não estás a seguir o Código da Estrada. É em relação à minha posição, ali eu bloqueio o caminho" (SP9).

41 Uma estratégia semelhante foi identificada na condução da VESV (Vidal-Gomel, 2010): numa rua de sentido único, com duas filas, o condutor coloca-se no meio para impedir que um veículo não se coloque ao seu lado e o não o atrapalhe no momento de virar.

\subsubsection{Evitar causar o pânico nos outros condutores}

Noutras situações, o desafio é garantir que os outros condutores não entrem em pânico e, assim, forçar a parar ou criar uma situação propícia a acidentes. Por exemplo, para poder entrar por entre as filas de trânsito em caso de engarrafamento, é preciso avisar os outros condutores para que eles cedam passagem. Os bombeiros adotam uma estratégia particular usando a sirene bem antes de chegar atrás dos veículos. Quando eles já estão atrás, é preciso desligar a sirene e utilizar os meios de comunicação apenas se for preciso transmitir alguma informação aos outros condutores. $O$ uso da sirene pode causar o pânico, o que aumentaria o risco de incidentes, ou a que parem e não se encostem não permitindo a passagem: "As pessoas têm medo, porque um grande camião que vem atrás é assustador, por isso é preciso antecipar a reação do condutor à frente ou do que está parado, que não sabe se deve parar" (SP9).

Além disso, nestas situações, trata-se também de se impor, mas em todos os casos, deixando uma margem de manobra, pois o comportamento dos outros condutores pode ser imprevisível: "Há sempre pessoas que não entendem, que nos procuram pelo retrovisor quando já estamos ali ao lado" (SP1). Vários indicadores do comportamento dos outros utilizadores da estrada são verbalizados a este propósito: "os movimentos de cabeça" (principalmente os motociclistas), "o comportamento das rodas", a frequência do acender das luzes de travagem: "intermitente".

o comportamento de outros utilizadores da estrada é uma das duas diferentes dimensões da dinâmica das situações de condução, em que, a priori, o condutor não tem qualquer possibilidade de ação ou de controlo - a outra dimensão é a inércia do veículo. Manter a fluidez da condução exige que se antecipe o comportamento dos outros, mas

Laboreal, Volume $10 \mathrm{~N}^{\circ} 1$ | 2014 
também que se encontrem maneiras de atrasar o menos possível, ou pelo menos evitar parar e fazer face a perigos ou incidentes. Trata-se então de proporcionar uma margem de segurança, ou reduzir a margem de manobra de outros utilizadores da estrada, para evitar um risco ou um obstáculo potencial e, assim, aumentar o tempo ou a distância que eles têm para reagir em caso de problema: limitando a atividade dos outros utilizadores, evitando o pânico, mas também apenas reduzindo a velocidade. Por exemplo, "Vi que virou e fez inversão de marcha. Portanto eu vi-a. É por isso que eu abrandei porque eu não sei exatamente se ela vai continuar a retroceder" (SP7). A aplicação de tais estratégias também depende da visibilidade e da infraestrutura, como outros motoristas relataram.

O conceito de "comportamento incerto", conceito pragmático identificado por Lefebvre (2001), resume bem esse conjunto, tanto em perceber a falta de previsibilidade do comportamento dos outros utilizadores da estrada, como de maneiras de lidar com isso: os indicadores permitem antecipar, os operacionais criam margem de manobra, incluindo a redução da dos outros utilizadores da estrada. Este conceito pragmático aparece, assim, no centro das estratégias dos motoristas. Mas a outro nível, estas estratégias respondem à exigência de uma condução fluida. Trata-se de um conceito organizador central que articula todos os outros conceitos e variáveis pragmáticas identificados da mesma forma que o revelou, sobre o tamanho das vinhas, Caens-Martin (2005). A diferença entre esses dois níveis de conceitos vem do seu carácter local versus genérico para dar conta da atividade. A fluidez da condução é a principal em todas as estratégias que analisamos nesta classe particular de situações que constitui a condução em situação de emergência.

o Esquema 1 sintetiza o conjunto de conceitos e variáveis que identificámos na condução dos bombeiros sapadores. Da seguinte verbalização damos conta de como ele foi desenvolvido: "Visto que estou a sair da rotunda, não vou apertar a faixa da direita, porque isso vai-me fazer cortar a minha curva porque era preciso que abrandasse um pouco mais do que se for à volta. Portanto, ali fui um pouco à larga e fui pela faixa da esquerda. Isso permitiu-me manter afastado da curva apertada e evitar abrandar; [não fazer a rotunda pelo exterior permite] reduzir a oscilação e aumentar a aderência dos pneus."

A estratégia do operacional visa reduzir a oscilação e aumentar a aderência dos pneus, ao sair da rotunda (infraestrutura). Essas três variáveis determinam o campo das trajetórias possíveis, com uma quarta variável: a velocidade. Mas esta tem uma função específica: para conseguir uma condução fluida, o operacional tenta manter a velocidade constante (e não é por isso uma variável). A fluidez da condução intervém em todas as estratégias analisadas, é um conceito pragmático organizador de atividade nesta classe de situações. 
Esquema 1: Conceitos e variáveis envolvidas na condução de veículos de socorro em situação de emergência por sapadores bombeiros
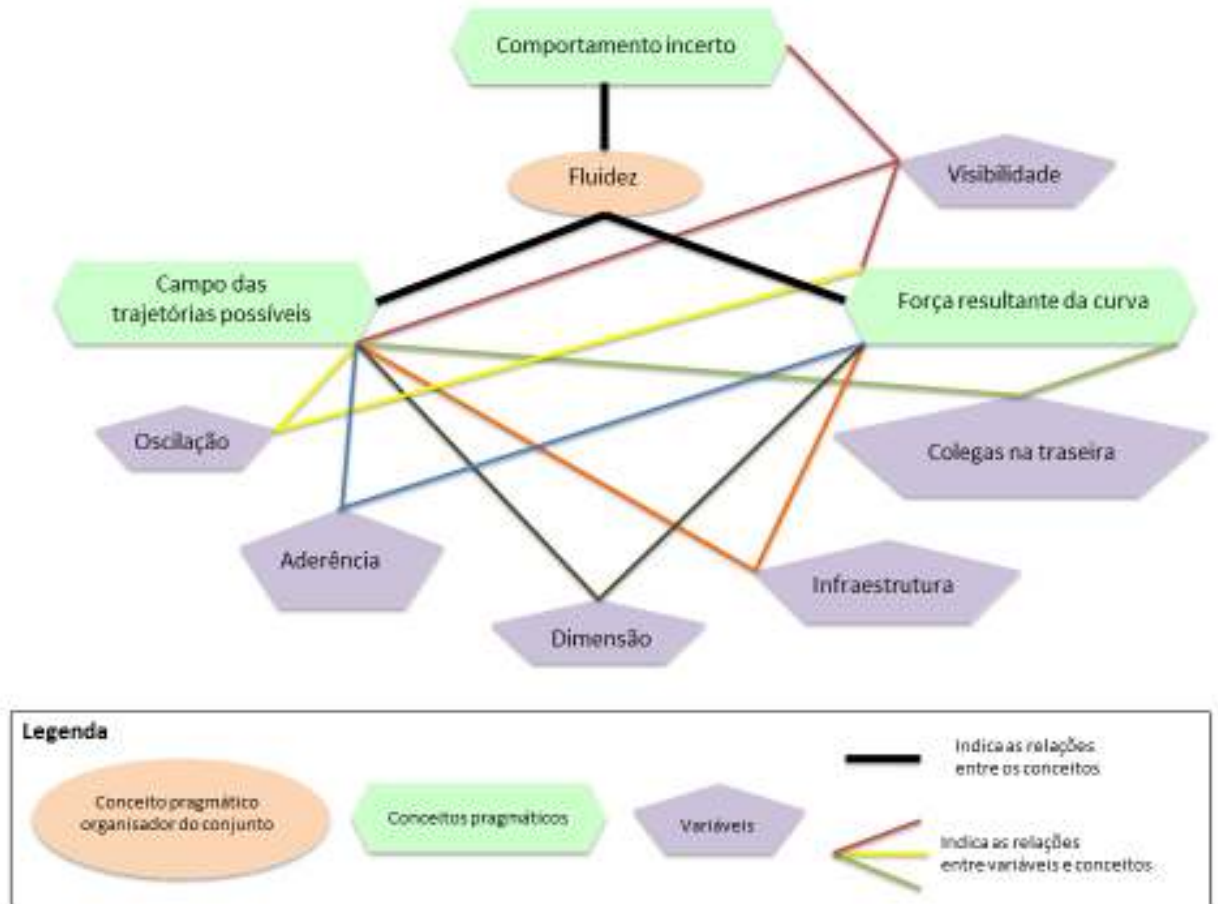

\section{As atividades e as competências coletivas dos condutores de veículos de socorro em situação de emergência}

\subsection{O binómio motorista - CG: entre colaboração e cooperação distribuída}

A atividade de condução é partilhada entre o motorista e o chefe da guarnição (CG) a vários níveis. Identificámos situações de colaboração e de cooperação distribuída para escolher o itinerário e o adaptar à situação, e situações de cooperação distribuídas ao longo da deslocação, o que também pode ter como objetivo "gerir os outros utilizadores da estrada".

\subsubsection{Colaboração e cooperação distribuída na escolha do itinerário e da sua} adaptação

Embora o CG seja o responsável pelo trajeto, a sua planificação e adaptação na prática é feita pelos dois bombeiros, com base no conhecimento da zona da intervenção e de situações de intervenção anteriores, como evidenciado pelas palavras destes dois operacionais:

- "Às vezes é muito difícil ler o mapa, isso depende de como se pega nele. Podes entrar num local por cima ou por baixo, e por isso, para algumas pessoas, orientar-se no mapa é um pouco difícil. Nesse momento, comunicas 
com o teu chefe, então às vezes vamos olhar para o mapa rapidamente para lhe dizer por onde vamos chegar. Isto pode ser nos dois sentidos, o chefe pode repreender o motorista que pensava conseguir passar por um lugar mas estava enganado" (SP9).

- "Então eu digo [ao CG], porque nós estávamos a entrar por ali como de costume [acesso principal], eu digo que em vez de entrar por ali, nós não sabemos como vai ser em relação à chamada que tivemos, eu disse-lhe que podemos ir pelas traseiras, pelo parque de estacionamento, extinguimos o fogo e partimos. Porque isto evita metermo-nos na boca do lobo. Por isso mudámos de opinião neste momento. Dissemos que se vai virar à direita ao chegar abaixo e não vamos seguir pelo acesso que normalmente seguimos" (SP10).

Estes dois exemplos mostram as fases de colaboração no binómio. Ao longo do trajeto, deparamo-nos com diferentes situações de cooperações distribuídas, semelhantes às que foram observadas por Parage \& Ferrand (2012) na condução de VESV. Assim, o CG:

- indica o trajeto ao motorista: "Se eu não conheço, eu levo-o até à cidade, e depois é o chefe da guarnição que orienta" (SP14);

- toma conta de uma parte da recolha de informações necessárias para a condução: "Desde logo, ele diz-me coisas sobre a minha condução que eu poderia não ver, um perigo, informações importantes. Se eu tenho uma má visibilidade à direita, ele pode dar-me informações e eu posso pedir-lhe" (SP7);

- também pode acionar a sirene.

\subsubsection{Cooperação distribuída entre o motorista e o CG para gerir outros utilizadores da estrada no contexto}

51 A sirene é usada para pedir prioridade aos outros utilizadores da estrada, para os prevenir em caso de má visibilidade e garantir que eles compreendam a situação: "Se houver falta de visibilidade ou há veículos, vamos ligá-la, vamos antecipar, preveni-los. Talvez as pessoas já nos tenham visto. Depois continuaremos a ligar, se vemos que alguns não entendem" (SP6).

Nas sequências que filmamos é o CG que aciona maioritariamente a sirene [13]. Um operacional explica a necessidade de antecipação do CG, e a tomada em conta das características das situações: "O CG deve antecipar a condução, pois aciona a sirene. [...] Por experiência, se se chega a uma rotunda, que ele vê claramente, provavelmente só vai ligar a sirene mais tarde, se ele não tem visibilidade vai ligar muito mais cedo" (SP3).

Estas utilizações da sirene pelo CG e as suas antecipações requerem conhecimento sobre a forma de conduzir do motorista e sobre os constrangimentos da condução. Assumimos que este conhecimento vem de uma consciência partilhada da situação, mesmo quando em alguns casos o motorista considera que o CG aciona a sirene tarde demais. Estas utilizações também são baseados na sincronização temporal das atividades, por causa da dependência temporal das ações a serem tomadas em relação à dinâmica do processo.

Observámos algumas situações em que o motorista liga ele próprio a sirene: "Quando o chefe da guarnição está muito ocupado, eu próprio ligo" (SP10).

Essas verbalizações, como as precedentes, dão conta da integração dos constrangimentos do colega de equipa. Podem ser interpretadas como um indicador de metacooperação (Hoc, 2001). 

pelos seus colegas ou pelo CG sobre a sua condução, por exemplo: "Eles criticam, se se passa uma lomba um pouco depressa ou uma curva mais apertada, eles são rápidos a dizer-te lá de trás "Atenção fomos sacudidos!"” (SP10). "Íamos em coluna e chegou a uma rotunda, eu estava ao lado dele, ele queria conduzir, muito bem. E depois, bom, eu sentia que ele queria mostrar o que sabia fazer. Só que ele chegou à rotunda, eu disse: "Ei, mais devagar aí!", primeira vez; "Ei, mais devagar!", eu disse-lhe pelo menos três vezes; "Vais muito depressa"” (SP10). Os colegas de equipa podem, portanto, agir sobre a condução quando esta lhes parece inadequada.

61 Estas regulações não se desenvolvem da mesma maneira independentemente da intervenção em que ocorrem. Também dependem do motivo da saída do piquete e do grau de gravidade esperado, que afetam emocionalmente o motorista e o coletivo, e podem afetar a condução: "É muito variável, é que depende da intervenção. Se não é muito importante, não rolas como com uma noção de gravidade comprovada [...] Depois, com o carácter de gravidade recebe-se muitas informações completas, entre o chefe da guarnição que 
prepara a intervenção, dá o ponto de encontro, prevê o material do pessoal. 0 pessoal que sob a pressão da adrenalina nos diz para nos apressarmos. Há uma multitude de informações que vão fundir-se na cabine e não se pode deixar que nos perturbe" (SP7). Um operacional diz, a propósito de um incêndio: "Há adrenalina para todos no camião. Eu não sei se temos tendência a conduzir depressa de mais... é a adrenalina. Sentimo-nos um pouco... sim, loucos!" (SP10).

62 A tripulação intervém na condução, se considerar que não é suficientemente fluida. Mas também acontece quando o CG ou a tripulação se deixam vencer pela emoção despertada pelo motivo da intervenção. $O$ motorista deve resistir a esta pressão. Ter consciência dos diferentes estados emocionais, dos seus efeitos sobre a condução e controlá-los advém dos metaconhecimentos que os motoristas têm que desenvolver (Lefebvre, 2001). A atividade de condução pode ser regulada a nível coletivo, como já apontado anteriormente. Isso é especificado por um bombeiro em autoconfrontação: "Há sempre um para canalizar a atmosfera" (SP3). Aqui, não se trata somente das competências individuais do motorista dirigidas ao coletivo, mas a capacidade do coletivo para se autorregular ou regular o comportamento de um dos seus membros, que vem da metacooperação (Hoc, 2001) e é uma dimensão importante das competências coletivas a adquirir.

\subsection{Conduzir preparando a intervenção para ajudar os colegas versus saber abstrair-se do coletivo}

63 As verbalizações entre os bombeiros sapadores podem ser numerosas durante os trajetos. Podem tratar-se de discussões dentro do veículo ou comunicações por rádio sobre a viagem ou sobre a própria intervenção, e ainda verbalizações mais pessoais. São ao mesmo tempo um meio de trocar informações e um desconforto; alguns operacionais relatam, então, a necessidade de se abstrair do coletivo.

O motorista pode estar a ouvir as ordens dadas pelo CG aos colegas da equipa porque a informação pode ser útil para identificar com precisão a localização da intervenção ou permitir-lhe compreender qual o colega que deve ajudar, como o ajudar e antecipar as suas necessidades. Por exemplo: "Saber como abastecer [ $\left.{ }^{14}\right]$, se vem outro camião abastecêlos, abrir os compartimentos do camião em função das necessidades dos colegas de equipa. [...] Saber onde estão os pontos de água, se é um incêndio de apartamento, se é em altura, o pessoal vai precisar rapidamente de uma escada que está no telhado por isso é precisar tirar as divisórias depressa para ter acesso às escadas. Se é um fogo benigno no lixo ou ao nível do chão, sabes que é só tirar a mangueira" (SP12). Aqui encontramos traços de metacooperações indispensáveis para a eficácia do coletivo (Hoc, 2001).

Outros operacionais evocam o inconveniente causado pelas interações durante a condução, pelo que se pode pensar que elas geram uma situação de dupla tarefa: “Temos que manter a concentração, não se deixar perturbar pelo que se passa dentro do camião [...] Eu tento não interagir a menos que seja sobre a minha condução, e o chefe da guarnição me dê uma ordem específica sobre a chegada aos locais, eu recebo a informação e eu vou não tratá-la logo de seguida" (SP7). Em alguns casos, as interações são fontes de riscos, como especifica um operacional: "E ali, há uma curva que é mesmo apertada e sente-se mesmo [...] Ali em E. é uma curva onde quase todos os veículos podem fugir de traseira. Basta que o chefe da guarnição diga nesse momento: quando chegares lá abaixo, deves seguir a estrada tal... e escutamos, não prestamos atenção à velocidade. Há falta de atenção e depois..." (SP3). Este exemplo destaca 
os metaconhecimentos a adquirir para, desta vez, se abstrair do coletivo e se concentrar na sua principal tarefa, o que contribui para a gestão dos riscos na estrada.

\subsection{O papel do coletivo de trabalho nas atividades construtivas}

Outras situações de condução, uma deslocação para atividades desportivas, por exemplo, são aproveitadas para apropriação das características do veículo, ou aprofundar os conhecimentos sobre as zonas em que se poderá ter que conduzir e identificar situações críticas, como relata um operacional: "É quando vamos para a piscina por exemplo, ou no regresso de uma intervenção se eu estiver na parte de trás do camião, que eles dizem "Posso ser eu a conduzir no regresso?". Isto permite aperceber-se da condução, da dimensão, e depois, é a cidade onde se trabalha, é a cidade onde vamos, portanto, escalar [ $\left.{ }^{15}\right]$ por isso "Aqui vamos levá-lo pelos caminhos difíceis". Sabemos que em I. há ruas pequenas que não são práticas para um pesado, é lá onde nós vamos apenas naquele dia em que se tem tempo para meter-se em locais de difícil acesso para que, no dia em que saibamos que é para onde vamos, sabermos se podemos passar ou não" (SP9). Este operacional também afirma que as situações são também transformadas tendo em vista a aprendizagem: "À tarde é a manobra [...] se se tem um jovem [...] ele deve trabalhar com o veículo para ver o que vale, fazêlo cometer alguns erros para ver a reação dele se isto não funciona".

Outros operacionais parecem estar cientes do papel das histórias transmitidas no seio do coletivo no desenvolvimento das competências dos motoristas e especialmente para a gestão dos riscos (Rogalski \& Leplat, 2011): "Estávamos todos na parte de trás de um camião, todos nós nos sentimos sacudidos, todos nós tivemos medo, uma vez, por isso ou era a experiência pessoal de ter medo ou a experiência de alguém que nos disse isso. Esta tarde, eu disse como eu me surpreendi, falamos entre nós e, em seguida, talvez possamos dizer que se ia rápido demais ou que se poderia ir de tal maneira. Saber que numa situação $X$ uma noite de chuva e na noite seguinte de chuva, não teremos as mesmas reações, é assim, nós sabemos. Então, sim, nós vivemos através, nos bombeiros há sempre anedotas. Vivemos através disso" (SP9).

O coletivo de trabalho contribui, portanto, para a criação de situações que promovem as atividades construtivas de partilha de saberes e o desenvolvimento das competências dos motoristas.

Assim, a atividade de condução para chegar ao local de um acidente é uma atividade em situação de emergência, coletiva e multidimensional. Inclui o trabalho coletivo do binómio motorista-CG, é dirigida aos colegas de equipa ao conduzir de forma fluida para não os sacudir e estando à escuta do CG para se preparar para os ajudar, a tripulação pode ser um meio de regulação coletiva das emoções e o coletivo de trabalho contribui para as atividades construtivas envolvidas no desenvolvimento das competências dos motoristas. Ao mesmo tempo, a condução, tarefa complexa, requer também ser-se capaz de se abstrair do coletivo para se concentrar.

\section{Conclusão e discussão}

Como referimos na introdução, a atividade de condução é marcadamente articulada com o trabalho e com as suas condições de realização (Forrierre \& Six, 2010; Fort, 
Pourcel Davezies, et al., 2010). O nosso estudo é consistente com estes resultados: conduzir veículos de socorro não é para os bombeiros sapadores apenas conduzir um veículo pesado. É também ter em conta a urgência da intervenção, sem gerar riscos de acidente na estrada, e uma atividade coletiva multidimensional, que inclui, por exemplo, ao mesmo tempo preparar a intervenção durante a atividade de condução e a distanciação das interações com os colegas para se concentrar na condução.

\subsection{Contribuições para a modelização da condução de veículos de socorro}

71 Apoiamo-nos no quadro da didática profissional (Samurçay \& Pastré 1995; Pastré, 2005) e no modelo de Lefebvre (2001) para caracterizar as competências dos condutores, incidindo sobre as estratégias implementadas e os conceitos pragmáticos e as variáveis que lhes estão subjacentes. Encontramos os conceitos identificados por Lefebvre: campo das trajetórias possíveis, força resultante da curva, comportamento incerto de outros utilizadores da estrada. Eles compreendem variáveis consideradas pelos bombeiros sapadores: a oscilação ou a aderência dos pneus, por exemplo. Mas eles são insuficientes para dar conta da organização da atividade de condução. O conceito pragmático organizador é o da fluidez da condução, o que permite explicar as estratégias analisadas. A fluidez da condução é uma resposta à contradição que foi enfatizada na frase "conduzir depressa lentamente", que nos deu um condutor de VESV para definir a condução em situações de emergência (Vidal-Gomel, 2010).

72 A análise da atividade em didática profissional não advém da análise da tarefa e dos conceitos e ou saberes que poderiam ser inferidos com base nisso. Neste caso, uma simples transposição dos conceitos identificados por Lefebvre para melhor ter em conta as características dos veículos seria suficiente. É, antes, uma análise da atividade tendo em conta, nomeadamente, as características das situações e os objetivos dos operacionais. É somente nessa base que podem ser recompostas as variáveis e conceitos aqui em jogo. Pode dizer-se que se trata de uma análise da tarefa cognitiva no que diz respeito à atividade e dos seus organizadores, para uma dada classe de situações; aqui a da condução de veículos de socorro em situação de emergência.

Além disso, nas situações estudadas, a atividade coletiva de condução não concerne apenas os outros utilizadores da estrada, como Lefebvre (op. cit) ou Mundutéguy \& Darses (2007) apontaram. Também diz respeito à cooperação com o chefe da guarnição, a ter em conta os colegas na parte de trás do veículo nas estratégias de condução, a preparação da intervenção para os ajudar, a regulação das emoções no coletivo ou o distanciamento do coletivo para se concentrar na condução. Assim, a atividade de condução de veículos de socorro (veículo de combate a incêndio pesado e veículo de socorro rodoviário) em situação de emergência é uma atividade coletiva multidimensional. Foram identificados vários aspetos das competências coletivas: estas derivam da consciência partilhada, mas também da metacooperação para a qual identificamos tanto dimensões cognitivas como emocionais, que se estende à noção de metacooperação desenvolvida por Hoc (2001) que não inclui este ultimo aspeto.

Se algumas dessas dimensões são específicas do trabalho dos bombeiros sapadores, outras são, sem dúvida, mais gerais. Assim, todos os condutores são obrigados a transportar passageiros, de modo que a consideração do seu conforto atrás - embora também dependa em parte do veículo conduzido - ou a regulação das emoções num 
coletivo, podem ser variáveis que poderiam ser analisadas noutros contextos para uma contribuição mais ampla para a formação dos motoristas.

\subsection{Pistas para a formação de bombeiros sapadores em condução em situação de emergência}

Estes primeiros resultados delineiam pistas de recomendações para a formação de motoristas de veículos de socorro em situação de emergência, mostrando a importância de levar em conta as estratégias de motoristas, que são, por vezes, diferentes das preconizadas pelos formadores. As variáveis e conceitos que organizam estas estratégias podem servir de base para construir ferramentas para a formação de especialização. Por exemplo, com base nas filmagens feitas, alloconfrontações coletivas (Mollo \& Falzon, 2004) podem ser realizadas; uma parte dos formadores da EDIS pode ser formado com base neste tipo de métodos. As variáveis e conceitos identificados (Esquema 1, acima) podem ser utilizados pelo formador para conduzir as entrevistas. Numa perspetiva da didática profissional, trata-se de munir o formador com esses conceitos e variáveis para que possam ser mobilizados na formulação de novas abordagens em função das características das situações visionadas. Devem promover assim a sua apropriação pelos atores interessados e constituir um recurso complementar para o desenvolvimento, como Samurçay \& Hoc (1996) mostraram a propósito de ferramentas para apoiar a condução de altos-fornos. A nossa hipótese é que isso pode ampliar o espaço de debate existente; por exemplo, na hora das refeições, quando se trocaram piadas entre os profissionais, como pudemos identificar. Este alargamento permitiria assim fortalecer o coletivo de trabalho (Caroly \& Barcellini, 2013), para se tornar consciente de suas próprias maneiras de fazer e descobrir as dos outros (Mollo \& Falzon, 2004), que são recursos para o desenvolvimento das competências dos atores.

Estes diferentes resultados levam a questionar a escolha organizacional de especialização dos motoristas. Em última análise, os chefes de guarnição não vão aprender a conduzir veículos de socorro em situação de emergência. A sua contribuição para a gestão de riscos através do uso da sirene e os seus controlos serão afetados. Pode, de facto, supor-se que a elaboração de um referencial operativo comum, da consciência partilhada da situação com o motorista depende das suas eventuais experiências comuns construídas ao longo do tempo, tornando-se mais difícil para eles a colaboração. Finalmente, se, como argumentam Caroly \& Clot (2004), o trabalho coletivo é uma condição do coletivo de trabalho, em última análise, teme-se que o seu contributo para a formação dos motoristas possa ficar enfraquecido. Por fim, a especialização pode levar a novos objetivos na formação, que deverá ter em conta a formação das atividades coletivas. Como, então, neste caso, formar o trabalho coletivo?

O "cross training" (Cannon-Bowers, Salas \& Converse, 1993) é um dispositivo que pode ser relevante para formar dimensões coletivas da condução em situações de emergência. Utilizando dramatizações, análises das tarefas e simulações, trata-se de fazer praticar todas as funções e tarefas dos diferentes membros da equipa por todos os membros do coletivo. Estas formações permitem fornecer a cada um informações sobre as tarefas, funções, equipamentos e outras situações e de compreender a interdependência dos papéis e responsabilidades, e assim favorecer a elaboração de modelos mentais partilhados (Salas \& Cannon-Bowers, 2000), e melhorar a consciência 
da situação (Bolstad, Cuevas, Costello \& Rousey, 2005). As variáveis e conceitos pragmáticos identificados poderiam ser incorporados em tais formações para facilitar a aquisição e partilha, por exemplo, utilizando-os para projetar dramatizações. Note-se que as situações de trabalho atuais (antes da especialização) partilham as características das formação de tipo "cross training": todos os atores podem ocupar todos os postos. Tratar-se-ia agora de recriar em situação de formação as características de situações reais que precisamente se tentou suprimir, situação paradoxal...

Contudo, as formações de tipo "cross-training" repousam também sobre simulações de situações em que os operacionais possam praticar em contextos relevantes e dispor de feedback (Salas \& Cannon-Bowers, 2000). Vários obstáculos teriam que ser levantados para que isso se tornasse efetivo, uma vez que tais formações não existem (do nosso conhecimento) nas Escolas departamentais de combate a incêndio e socorro: 1) o projeto é geralmente caro; 2) os formadores não podem realizar formação simulada em situações reais, sem transgredir os regulamentos em vigor; 3 ) estas diferentes situações de formação não parecem conseguir traduzir as dimensões emocionais envolvidas na atividade de condução em situação de emergência, o que torna difícil formar em aspetos como a regulação coletiva das emoções ligadas ao motivo da saída para intervenção.

Outra forma seria a de concentrar-se nos bombeiros sapadores de Paris para os quais a especialização em condução está em vigor há vários anos e que têm a reputação de ser um corpo de elite. Tratar-se-ia, então, de entender o que constitui a eficiência coletiva e de transpor para a formação determinadas características do seu funcionamento.

Outras questões permanecem: a especialização em condução pode enfraquecer o coletivo de trabalho. Assim, pode-se perguntar se as atividades construtivas que ocorrem fora das situações de trabalho, tais como as aprendizagens que são realizáveis no caminho para os locais de treino desportivo, poderão persistir. Os resultados de estudos anteriores sobre o "cross training" não indicam qualquer efeito particular que permitisse solucionar isso. Devem ser postos em prática outros tipos de dispositivos. Assim, para promover o desenvolvimento do coletivo, Caroly \& Barcellini (2013) abrem algumas pistas, como: tentar melhor compreender e reconhecer as competências e a qualidade de trabalho, que podem ser baseadas em métodos de explicitação do trabalho e de alloconfrontações ou a criação de espaços para se debaterem maneiras de trabalhar.

81 Assim, a decisão de especialização dos motoristas dos bombeiros sapadores levou a que estes "profissionais móveis" - ou seja, aqueles para quem conduzir é uma tarefa tão secundária como essencial, de acordo com a categoria de Gressel \& Mundutéguy (2008) - se tornem "especialistas de transporte" - ou seja, os profissionais cuja principal tarefa é desta vez o transporte - num coletivo cujas missões permanecem inalteradas. Esta decisão não só prejudica a realização da atividade no contexto e a gestão de riscos, mas também cria novos desafios para a formação de operacionais e exige novos meios. $\mathrm{Na}$ verdade, muitas das regulações que foram aprendidas em situações de trabalho, inclusive dentro do coletivo, e que contribuíram para a gestão dos riscos, recaem ainda mais na formação. 


\section{BIBLIOGRAFIA}

Barthe, B., \& Queinnec, Y. (1999). Terminologie et perspectives d'analyse du travail collectif en ergonomie. L'Année psychologique, 99, 663-686.

Bolstad, C.A., Cuevas, H.M., Costello, A.M., \& Rousey, J. (2005). Improving Situation Awareness through Cross-Training. In Proceeding of the $49^{\text {th }}$ Congres of Human Factors \& Ergonomics Society. USA: Orlando (FL).

Caens-Martin, S. (2005). Concevoir un simulateur pour apprendre à gérer un système vivant à des fins de production: la taille de la vigne. In P. Pastré (Coord.), Apprendre par la simulation. De l'analyse du travail aux apprentissages professionnels (pp. 81-106). Toulouse: Octarès.

Cannon-Bowers, J. A., Salas, E., \& Converse, S. A. (1993). Shared mental models in expert team decison making. In N. J. Castellan (Coord.), Current issues in individual and group decision making (pp. 221-246). Hillsdale: Erlbaum.

Caroly, S., \& Barcellini, F. (2013). Le développement de l'activité collective. In P. Falzon (Coord.), Ergonomie constructive (pp. 33-45). Paris: PUF.

Caroly, S., \& Clot, Y. (2004). Du travail collectif au collectif de travail: développer les stratégies d'expérience. Formation Emploi, 88, 43-55.

Chalandon, X. (2003). Situation awareness en conception système. Actes du Colloque EPIQUE 2003: «Deuxièmes journées d'études en psychologie ergonomique». Boulogne Billancourt: 2-3 octobre 2003 (en ligne: http://sfpsy.org/spe-grape/Actes-Epique-2003/EPIQUE2003Actes\%281\%29.pdf).

Clot, Y. (1999). La fonction psychologique du travail. Paris: PUF.

Cru, D. (1988). Collectif et travail de métier. In C. Dejours (Coord.). Plaisir et souffrance dans le travail (pp. 43-49). Paris: Editions de l'AOCIP.

Daniellou, F. (1992). Le statut de la pratique et des connaissances dans l'intégration ergonomique de conception. Thèse d'habilitation à diriger des recherches. Toulouse: Université de Toulouse - Le Mirail (juin 1992).

Endsley, M. R. (1995). Toward a theory of situation awareness in dynamic systems. Human Factors, $37,32-64$.

Falkmer, T., \& Nordmark, S. (2002). Truck simulator feasibility study. Rapport européen TrainerGRD1-1999-10024. CEE: Commission Internationale des Examens de Conduite Automobile.

Forrierre, J., \& Six, F. (2010). Comprendre le risque routier professionnel par l'analyse de l'activité. L'exemple des conducteurs de travaux. Pistes, 12(2). http://www.pistes.uqam.ca/v12n2/ articles/v12n2a5.htm

Fort, E., Pourcel, L, Davezies, P, Renaux, C, Chiron, M, \& Charbotel, B. (2010). Road accidents, an occupational risk. Safety science, 48(10), 1412-20.

Giboin, A. (2004). La construction de référentiels opératifs communs dans le travail coopératif. In J.-M. Hoc \& F. Darses (Coord.), Psychologie ergonomique: tendances actuelles (pp. 119-139). Paris: PUF. Gressel, R., \& Mundutéguy, C. (2008). Les professionnels mobiles: Un groupe hétérogène avec une exposition importante au risque routier. Recherche Transports Sécurité, 99, 147-167.

Hoc, J.-M. (1996). Supervision et contrôle de processus. La cognition en situation dynamique. Grenoble: PUG. 
Hoc, J.-M. (2001). Toward a cognitive approach to human-machine coopération in dynamic situations. Intenational journal of human-computer studies, 54, 509-540.

Kaber, D. B., \& Endsley, M. R. (1998). Team situation awareness for process control. Safety and performance. Process Safety Progress, 17(1), 43-51.

Largier, A., Delgoulet, C., \& De La Garza, C. (2008). Quelle prise en compte des compétences collectives et distribuées pour une gestion des compétences professionnelles? Pistes, 10(1),

http://www.pistes.uqam.ca/v10n1/articles/v10n1a3.htm.

Lefebvre, C. (2001). Vers une formation à la conduite automobile intégrant des connaissances conceptuelles et les métaconnaissances. Recherche-transports-sécurité, 70, 16-40.

Leplat, J. (2000). L'analyse psychologique de l'activité en ergonomie. Toulouse: Octarès.

Michon, J. A. (1985). A critical view of driver behavior models. What do we know, what should we do? In L. Evans \& R. Schwing (Coord.), Human behavior and traffic safety (pp. 485-525). New York: Plenum press.

Mollo, V., \& Falzon, P. (2004). Auto- and allo-confrontation as tools for reflective activities. Applied Ergonomics, 35(6), 531-540.

Montmollin, M. (de) (1984). L'intelligence de la tâche. Eléments d'ergonomie cognitive. Berne: Peter Lang.

Munduteguy, C., \& Darses, F. (2007). Perception et anticipation du comportement d'autrui en situation simulée de conduite automobile. Le travail humain, 70(1), 1-32

Neboit, M. (1978). Simulation et apprentissage de la conduite automobile. Le travail humain, 41(2), 239-249.

Parage, P., \& Ferrand, D. (2012). L'analyse de l'activité de conduite en situation d'urgence chez les sapeurs pompiers: lorsque l'ingénierie didactique questionne le management. Actes $d u 2^{\circ}$ Colloque international de didactique professionnelle «Apprentissage et développement professionnel» (atelier 25). Nantes (France): 7 et 8 juin 2012, CREN-Université de Nantes-RPDP, http://www.didactiqueprofessionnelle.org/.

Pastré, P. (2005). La conception de situations didactiques à la lumière de la théorie de la conceptualisation dans l'action. In P. Rabardel \& P. Pastré (Coord.), Modèles du sujet pour la conception. Dialectiques activités développement (pp. 73-107). Toulouse: Octarès

Pastré, P. (Coord.) (2005 b). Apprendre par la simulation. De l'analyse du travail aux apprentissages professionnels. Toulouse: Octarès.

Reynaud, J.-D. (2001). Le management par les compétences: un essai d'analyse. Sociologie du travail, 43(1), 7-31.

Rogalski, J. (1994). Formation aux activités collectives. Le travail humain, 54(4), 367-386.

Rogalski, J. (2005). Le travail collaboratif dans la réalisation des tâches collectives. In J. Lautrey \& J.-F. Richard (Coord.). L'intelligence (pp. 75-87). Paris: Lavoisier.

Rogalski, J., \& Leplat, J. (2011). L'expérience professionnelle : expériences sédimentées et expériences épisodiques. @ctivités, 8(2), 4-31.

Salas, E., \& Cannon-Bowers, J. A. (2000). The anatomy of team training. In S. Tobias \& J. D. Fletcher (Coord.), Training \& retraining. A handbook for business, industry, governement, and the military (pp. 312-335). New York/London: Macmillan reference USA. 
Salas, E., Prince, C., Baker, D. P. \& Shrestha, L. (1995). Situation awareness in team performance: implications for measurement and training. Human Factors, 37, 123-136.

Salas, E., Rosen, M. A., Burke, C. S., Nicholson, D., \& Howse, W. R. (2007). Markers for enhancing team cognition in complex environments: the power of team performance diagnosis. Aviation, space and environnemental Medicine, 78(5, section II), B77-85.

Samurçay, R., \& Hoc, J.-M. (1996). Causal versus topographical supports for diagnosis in dynamic situations. Le Travail Humain, 59, 45-68.

Samurçay, R., \& Pastré, P. (1995) La conceptualisation des situations de travail dans la formation des compétences. Éducation Permanente, 123, 13-31.

Samurçay, R., \& Rabardel, P. (2004). Modèle pour l'analyse de l'activité et des compétences. Propositions. In R. Samurçay \& P. Pastré (Coord.), Recherches en didactique professionnelle (pp. 133-180). Toulouse: Octarés.

Terssac, G. (de), \& Chabaud, C. (1990), Référentiel opératif commun et fiabilité. In J. Leplat et G. de Terssac (Coord.), Les Facteurs humaines de la fiabilité dans les systèmes complexes (pp. 111-139). Toulouse: Octarès.

Têtard, C., Quincy, R., Rougemoux, J.-P., \& Vulin, D. (1992). L'insécurité des poids lourds dans les longues descentes. Rapport INRETS n¹52. Paris (France) : INRETS.

Valot, C. (2001). Rôles de la métacognition dans la gestion des environnements dynamiques. Psychologie française, 46(2), 131-141

Van der Molen, H. H., \& Bötticher, A. M. T. (1988). A hierarchical risk model for traffic participants. Ergonomics, 31(4), 537-555.

Vidal-Gomel, C. (2010). Les apports de la didactique professionnelle. L'exemple de l'anticipation du comportement des usagers de l'espace routier par les conducteurs de VSAV. Communication présentée au séminaire du Service départemental d'incendie et de secours de l'Essonne: «Capitalisation des compétences au service de la formation professionnelle dans le domaine de la conduite chez les sapeurs-pompiers». Fleury-Mérogis (France): 11 février 2010.

Vidal-Gomel, C., \& Rogalski, J. (2007). La conceptualisation et la place des concepts pragmatiques dans l'activité professionnelle et le développement des compétences. @ctivités, 4(1), pp 49-84, http://www.activites.org/v4n1/v4n1.pdf.

\section{NOTAS}

1. Gressel e Mundutéguy (2008) propõem que se distinga entre "os profissionais de transporte" para quem a deslocação é a principal tarefa ou função (motoristas de táxi ou de pesados de passageiros, por exemplo) e "profissionais móveis" para quem a deslocação é uma tarefa secundária mas essencial para alcançar a sua principal missão ou tarefa. Bombeiros pertencem à segunda categoria. É por esta razão que usamos o termo "não- profissionais da estrada".

2. Neste texto, as competências são definidas como "conjuntos estabilizados de saberes e saberesfazer, de condutas tipo, procedimentos padrão, tipos de raciocínio, que podem ser postas em açã sem nova aprendizagem. As competências sedimentam e estruturam as aquisições de conhecimentos na história profissional; eles permitem a antecipação dos fenómenos, o implícito nas instruções, a variabilidade na tarefa" (de Montmollin, 1984, p. 121-122).

3. O conceito de "situation awareness" foi introduzido por Endsley (1995) para explicar a compreensão de situações com um objetivo de ação em ambientes dinâmicos. Entre as suas 
características retemos nomeadamente o facto de que será mais ou menos consciente. Chalandon (2003), por exemplo, apresenta uma síntese desta ideia.

4. Os conceitos pragmáticos são entidades que estruturam e organizam a atividade. Estes são invariantes operatórios. Este conceito é apresentado em detalhe em Vidal-Gomel e Rogalski (2007).

5. É o chefe da guarnição que lidera a intervenção. No entanto, ele não é hierarquicamente superior ao motorista.

6. Um aviso sonoro usado pelos bombeiros em situações de emergência para comunicarem com os outros utilizadores da estrada.

7. Ou seja, com o pessoal e o material.

8. Tomamos como referência um período de 2 meses em 2010, sobre o qual dispúnhamos dos dados necessários.

9. Antiguidade média na profissão: 23 anos (desvio-padrão: 4; mín.: 18; máx.: 28); antiguidade média da posse de carta de condução categoria B: 24 anos (mín.: 19; máx.: 33; desvio-padrão: 5,4); antiguidade média da posse de carta de condução de pesados: 21,6 anos (mín.: 19; máx.: 23; desvio-padrão: 1,95). Estes dados são a título indicativo; não foram trabalhados na análise.

10. Por questões de espaço no habitáculo do veículo e de segurança.

11. Idade média: 34,5 anos (mín.: 27; máx.: 45; desvio-padrão: 5,4); antiguidade na profissão média: 9,9 anos (desvio padrão: 6,5; mín.: 5; máx.: 26); antiguidade média da posse de carta de condução categoria B: 15,8 anos (mín.: 7; máx. 27; desvio-padrão: 5,9); antiguidade média da posse de carta de condução de pesados: 11,4 anos (mín.: 2; máx.: 23; desvio-padrão: 6,9). Estes dados são a título indicativo; não foram trabalhados na análise.

12. Extratos das verbalizações estão incluídos no texto, seguido por um código para distinguir os bombeiros: por exemplo, SP3 corresponde a sapador bombeiro n. ${ }^{\circ} 3$.

13. Não nenhuma regra prescrita sobre o acionar da sirene. A conceção do tablier das viaturas permite ao $C G$ acionar a sirene facilmente.

14. Isto é, ligar a mangueira do camião de combate a incêndio a uma boca-de-incêndio no local da intervenção.

15. Entrar ao serviço.

\section{RESUMOS}

O presente estudo foi realizado a pedido de uma escola departamental de combate ao incêndio e socorro de bombeiros sapadores em França. Desenvolvido com base nas abordagens da ergonomia e da didática profissional, trata-se aqui de realizar uma análise da atividade de condução de dois veículos em situações de emergência, no sentido de melhorar a formação em condução num contexto de especialização de motoristas. A partir de entrevistas, de filmagens de saídas do piquete e de autoconfrontações, mostramos que se trata de uma atividade coletiva multidimensional e identificamos diferentes estratégias de condução, que são organizadas pelo conceito pragmático de fluidez de condução. Estas estratégias podem então ser utilizadas para servir o duplo objetivo de uma saída de piquete em situação de emergência: chegar o mais rápido possível ao local da ocorrência evitando incidentes no caminho. Os resultados destacam as limitações da formação atual e as armadilhas que surgem na especialização dos motoristas. 
El presente estudio se realizó a petición de una escuela departamental de lucha contra incendios y socorro de bomberos en Francia. Desarrollado sobre la base de los enfoques de la ergonomía y de la didáctica profesional, se llevó a cabo un análisis de la actividad de conducción de dos vehículos, en situaciones de emergencia, para mejorar la formación en conducción en un contexto de especialización de conductores. A través de entrevistas, grabaciones vídeo de salidas de equipos de primera intervención y de auto-confrontaciones, mostramos que se trata de una actividad colectiva multidimensional e identificamos diferentes estrategias de conducción, que están organizadas por el concepto pragmático de fluidez de conducción. Estas estrategias se pueden utilizar para responder al doble propósito de una salida de equipos de primera intervención en situaciones de emergencia: llegar lo más pronto posible al lugar del siniestro, evitando incidentes en la ruta. Los resultados destacan las limitaciones de la formación actual y las trampas que surgen en la especialización de los conductores.

L'étude présentée a été réalisée à la demande d'une école départementale d'incendie et de secours des sapeurs-pompiers en France. Sur la base d'approches développées en ergonomie et didactique professionnelle, il s'agit de mener une analyse de l'activité de conduite de deux engins en situation d'urgence, en vue d'améliorer la formation à la conduite dispensée dans un contexte de spécialisation des conducteurs. A partir d'entretiens, de films de départs en intervention et d'autoconfrontations, nous montrons qu'il s'agit d'une activité collective multidimensionnelle et nous identifions différentes stratégies de conduite, qui sont organisées par le concept pragmatique de fluidité de la conduite. Ces stratégies permettent alors de répondre au double objectif d'un départ en intervention : arriver le plus vite possible sur le lieu du sinistre tout en évitant tout incident routier. L'ensemble de ces résultats souligne les limites de la formation actuelle ainsi que les écueils de la spécialisation des conducteurs.

This study was requested by a departmental firefighting and rescue school for firefighters in France. Based on ergonomics and professional didactics approaches, the aim is to analyze the activity of driving two emergency vehicles so to improve the training in the drivers' specialization context. Based on interviews, observation recordings of emergency departures and self-confrontations, we showed that it is a collective, multidimensional activity and we identified different driving strategies, organized according to the pragmatic concept of "fluidity of traffic". These strategies may then be used to serve the dual-purpose of a standby patrol service when called for an emergency: to arrive on site as fast as possible and to avoid every road incident. The findings highlight the limits of the current training program and the traps that come along the drivers' specialization.

\section{ÍNDICE}

Palavras-chave: condução do camião, intervenções de emergência, competências coletivas, análise da atividade, formação

Keywords: heavy trucks driving, emergency service, collective skills, activity analysis, training Mots-clés: conduite de poids lourds, intervention d'urgence, compétences collectives, analyse de l'activité, formation

Palabras claves: conducción de camiones, intervenciones de emergencia, competencias colectivas, análisis de la actividad, formación 


\section{AUTORES}

\section{CHRISTINE VIDAL-GOMEL}

CREN-Université de Nantes, Département des sciences de l'éducation, Chemin de la Censive du Tertre, BP 81227, F-44312 Nantes cedex 3,

christine.vidal-gomel@univ-nantes.fr

\section{CATHERINE DELGOULET}

LATI-Université Paris Descartes, Institut de psychologie, 71 avenue Edouard, Vaillant, F-92774 Boulogne-Billancourt cedex

catherine.delgoulet@parisdescartes.fr

\section{CÉLINE GEOFFROY}

Université de Nantes, Département des sciences de l'éducation, Chemin de la Censive du Tertre, BP 81227, F-44312 Nantes cedex 3

celine.geffroy@etu.univ-nantes.fr 